\title{
Fire Resistance of Concrete-Filled Box Columns Fabricated with Different Welding Methods
}

\author{
Chao-Wei Tang and Cheng-Yi Chen ${ }^{1 *}$ \\ Department of Civil Engineering and Geomatics, Cheng Shiu University \\ No. 840, Chengcing Rd., Niaosong Dist., Kaohsiung 83347, Taiwan \\ ${ }^{1}$ Department of Electrical Engineering, Cheng Shiu University \\ No. 840, Chengcing Rd., Niaosong Dist., Kaohsiung 83347, Taiwan
}

(Received August 30, 2016; accepted December 27, 2016)

Keywords: concrete-filled box column, fire resistance, complete penetration weld, partial penetration weld

In this study, a series of two full-scale experiments were carried out to investigate the effects of welding method on the fire resistance of concrete-filled box columns (CFBCs). The column specimens were all square sections $500 \times 500 \mathrm{~mm}^{2}$ in size and $4350 \mathrm{~mm}$ high and were filled with high-strength concrete. Specimen CP1 was fabricated by a complete penetration weld while specimen PP1 was fabricated by a partial penetration weld. The tested columns were subjected to a constant compression load throughout the test period. The applied load corresponded to $28 \%$ of the design value of the buckling resistance of the column at room temperature. Test results indicate that the fire resistance of specimen CP1 was $55 \mathrm{~min}$, compared with $51 \mathrm{~min}$ for specimen PP1. As a result, it can be concluded that under a load level of 0.28 , the effect of different welding methods on the fire resistance of CFBC was not very significant. In addition, the established numerical model was able to reasonably predict the axial deformation of the tested columns.

\section{Introduction}

Fire often leads to failure or collapse of the column members in a building structure, resulting in a severe disaster. Therefore, in the design of buildings for fire protection, the fire resistance of columns is very important. In general, the structural fire protection requirements contained in most building codes represent the minimum fire rating deemed acceptable by their countries. Basically, most codes generally require load-bearing components and assemblies to have a fire resistance rating at least equal to that required for the supported assembly (floor or roof).

Steel reinforced concrete (SRC) components have many advantages and have been widely used in high-rise buildings. In particular, concrete-filled box columns (CFBCs) possess excellent structural behavior. ${ }^{(1-3)}$ They offer a practical solution for providing fire protection to hollow structural steel columns without any external protection. Therefore, steel-reinforced concrete columns have been used in various building projects to great advantage throughout the world in the last decade. ${ }^{(4-11)}$ However, relatively little research has been conducted on the effects of welding methods on the fire resistance of CFBC.

"Corresponding author: e-mail: k0464@gcloud.csu.edu.tw http://dx.doi.org/10.18494/SAM.2017.1518 
To promote the applications of CFBC in Taiwan, in this study we aim to examine the fire behavior of CFBC fabricated by a complete penetration weld and a partial penetration weld.

\section{Experimental Program}

A series of two full-scale fire experiments were carried out to investigate the effect of welding methods on the fire resistance of CFBC. The specimen labels, dimensions, and material properties of the two columns are given in Table 1 , where $D, t$, and $L$ refer to the cross-sectional dimension, steel thickness, and specimen length in $\mathrm{mm}$. The column specimens were all square sections 500 $\times 500 \mathrm{~mm}^{2}$ in size and $4350 \mathrm{~mm}$ high and were filled with high-strength concrete. All of the steel sections of the CFBC specimens were fabricated from a steel plate $22 \mathrm{~mm}$ thick. These plates were joined by longitudinal fillet welds at the vertices as shown in Fig. 1. In addition, Fig. 2 shows that each CFBC had end plates welded to them in order to transmit an axial load. End stiffeners were also provided to ensure that end conditions did not affect the failure resistance of the thermal load.

Table 1

Specimen labels, dimensions, and material properties for test columns.

\begin{tabular}{lcc}
\hline Specimen number & CP1 & PP1 \\
\hline Welding method & Complete penetration weld & Partial penetration weld \\
Sectional dimension $D \times t \times L\left(\mathrm{~mm}^{3}\right)$ & $500 \times 22 \times 4350$ & $500 \times 22 \times 4350$ \\
Yield strength of steel plate $(\mathrm{MPa})$ & 362.8 & 362.8 \\
Concrete strength $(\mathrm{MPa})$ & 51.4 & 51.4 \\
Nominal column squash load $(\mathrm{kN})$ & 18002.6 & 18002.6
\end{tabular}

Notes: $D=$ cross-sectional dimension; $t=$ steel thickness; $L=$ specimen length.

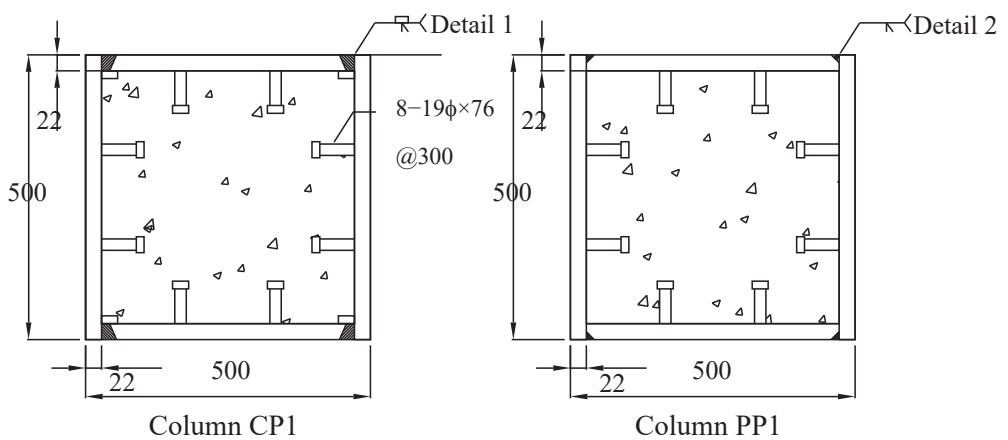

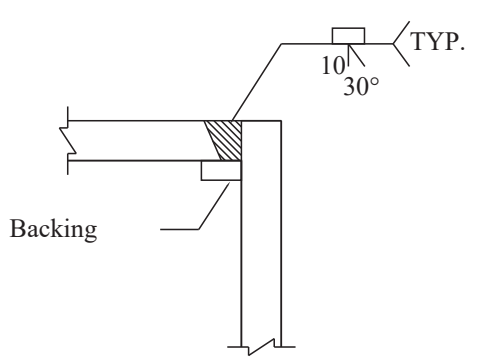

Detail 1

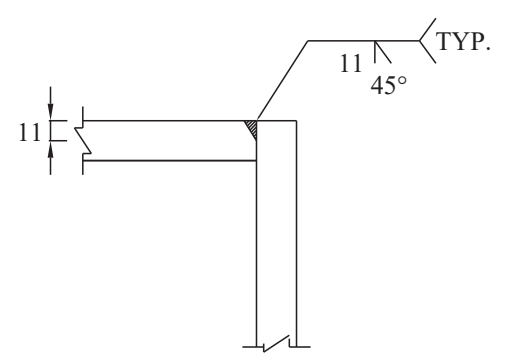

Detail 2

Fig. 1. Cross section of CFBC. 


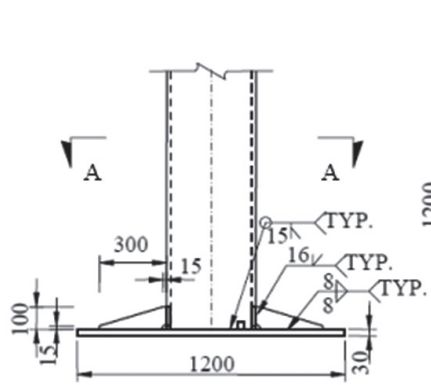

End plate of column

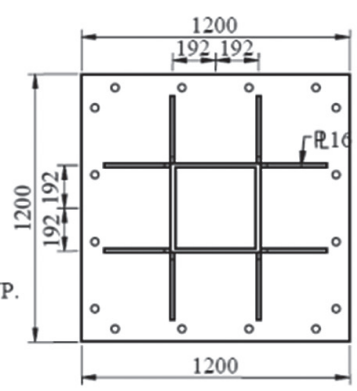

Section A-A
Fig. 2. End plate of CFBC.

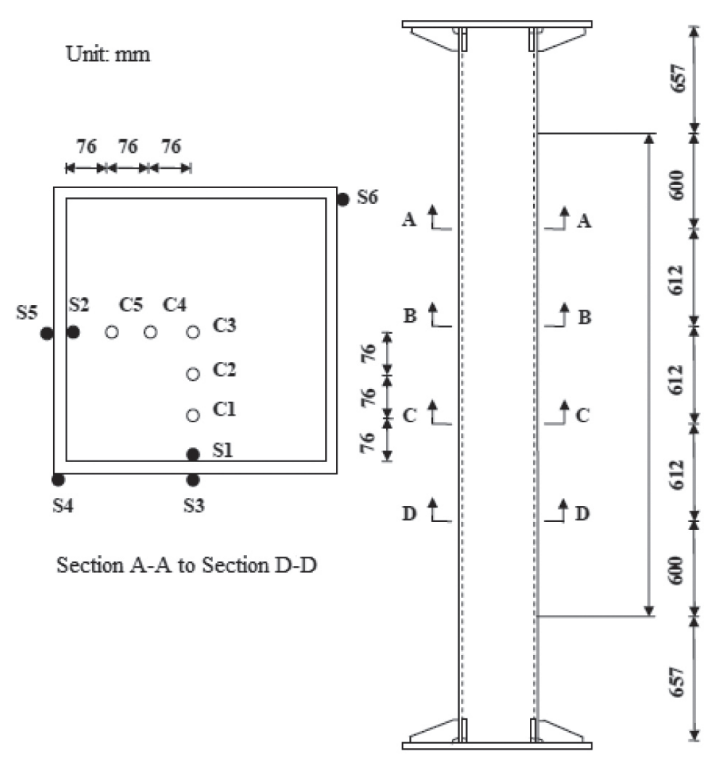

Fig. 3. Schematic thermocouple layout of CFBC.

The temperature from the specimen's surface to the inner central core was measured with type $\mathrm{K}$ thermocouples located at different depths in four sections of the column as represented in Fig. 3. As can be seen from Fig. 3, the thermocouples S1-S6 were welded to the surface of the steel plate and the thermocouples $\mathrm{C} 1-\mathrm{C} 5$ were embedded in the concrete core. In the fire test, three different linear variable displacement transducers (LVDTs) were used to measure the axial displacement of the column specimens. They were placed on the top and bottom of the test columns. Moreover, a numerical model was established for predicting the axial deformations of the CFBC at elevated temperatures, and thus making a comparison with the experimental values.

During the entire test, the columns were subjected to a constant compression load of $4969 \mathrm{kN}$. The applied load was controlled by a 19.6 MN load cell, located on the head of the piston of a jack. The applied load corresponded to $28 \%$ of the design value for the buckling resistance of the column at room temperature. Thermal load was applied on the columns in the form of an International Organization for Standardization (ISO) 834 time-temperature curve in a natural gas-fired large-scale laboratory furnace until the experimental termination conditions were reached.

\section{Test Results}

Figure 4 shows a comparison between the evolution of the mean temperature in the furnace for all the fire resistance tests and the ISO 834 standard fire curve. A difference between them was observed in the first $15 \mathrm{~min}$ of heating because some of the nozzles failed to ignite. Over $15 \mathrm{~min}$, however, the temperature followed the ISO 834 standard fire curve closely and was very uniform in the two tests.

The axial deformation of the column was a function of time as shown in Fig. 5. Evidently, the columns experienced an expansion phase before being compressed to failure because the axial load level was low. Figure 5(a) shows that the axial deformation of specimen CP1 increased with the 


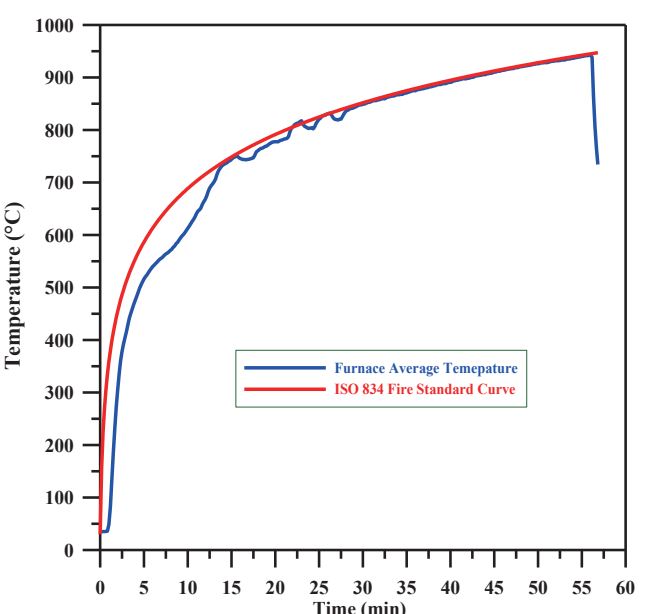

(a)

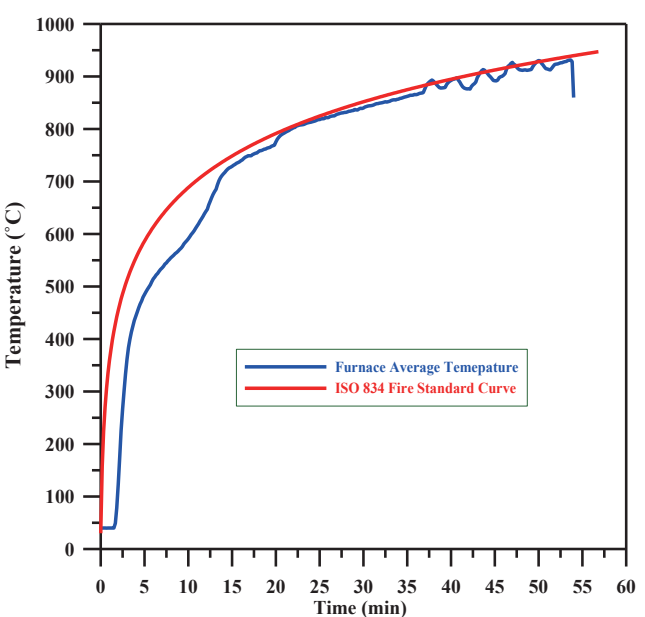

(b)

Fig. 4. (Color online) Temperature in the furnace: (a) specimen CP1 and (b) specimen PP1.

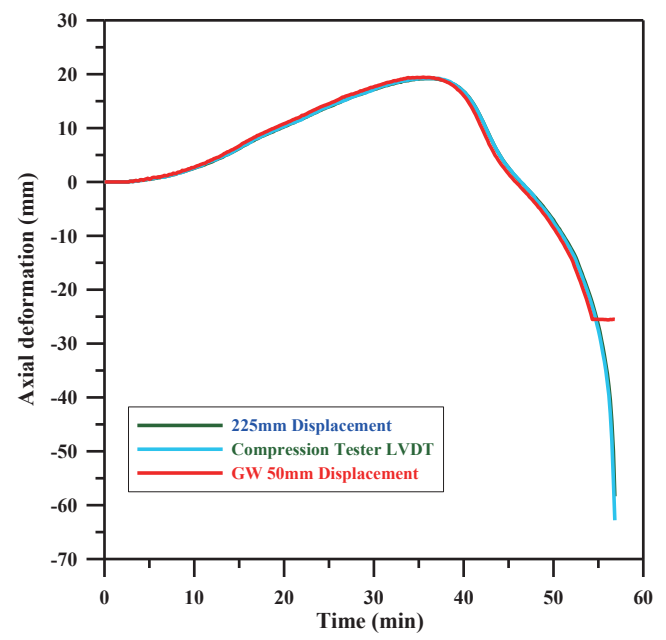

(a)

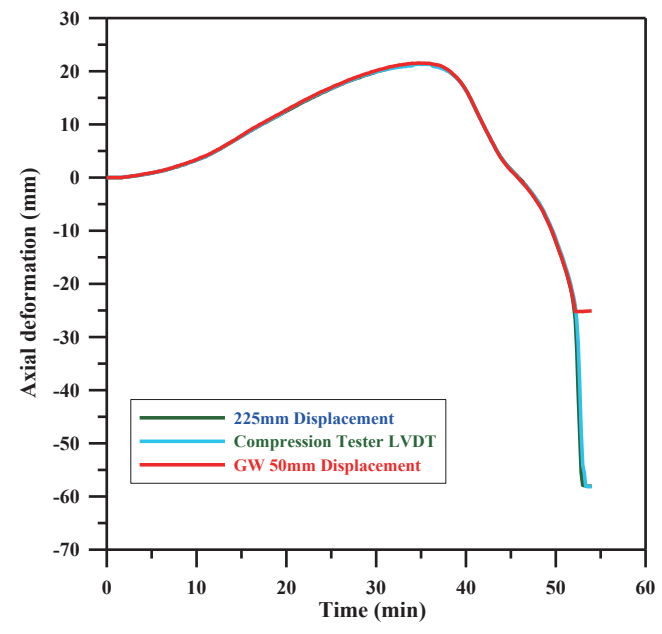

(b)

Fig. 5. (Color online) Axial deformation in CFBC as a function of exposure time: (a) specimen CP1 and (b) specimen PP1.

duration of the fire test up to $36 \mathrm{~min}$. The maximum axial elongation was $19.2 \mathrm{~mm}$. Then, the axial elongation of the specimen gradually decreased. Furthermore, the specimen exhibited compression at $46 \mathrm{~min}$. After $56 \mathrm{~min}$ of test, the specimen had an axial compression strain rate of $13.8 \mathrm{~mm} / \mathrm{min}$ and had reached the test termination conditions $(13.05 \mathrm{~mm} / \mathrm{min})$. Therefore, the test was terminated at 56 min. On the other hand, Fig. 5(b) shows that the axial deformation of specimen PP1 increased with the duration of fire test up to $34 \mathrm{~min}$. The maximum axial elongation was $21.3 \mathrm{~mm}$. Similarly, the axial elongation of the specimen was then gradually reduced. The specimen exhibited compression at $45 \mathrm{~min}$. Subsequently, the test was terminated at $52 \mathrm{~min}$. In general, the test results indicate that the fire resistance of the CFBC was limited to about $1 \mathrm{~h}$. This trend clearly indicated a rapid increase in contraction before collapse as shown in Fig. 5. Failure was due to rapid crack propagation in the concrete, resulting in the premature failure of the concrete core. 
Figure 6 shows the evolution of temperature at cross-section A for specimen CP1. Test results indicated that specimen $\mathrm{CP} 1$ reached a fire resistance rating of $55 \mathrm{~min}$. In addition, the highest temperature in the concrete was only $290{ }^{\circ} \mathrm{C}$ while that in the structural steel was $724{ }^{\circ} \mathrm{C}$. As for specimen PP1, test results indicated that it reached a fire resistance rating of $51 \mathrm{~min}$. Figure 7 shows that the measured temperatures at cross-section A were also a function of time. Furthermore, the highest temperature in the concrete was only $265{ }^{\circ} \mathrm{C}$ while that in the structural steel was 723 ${ }^{\circ} \mathrm{C}$. The test results showed that there was no significant difference in the temperature distribution within the two specimens.

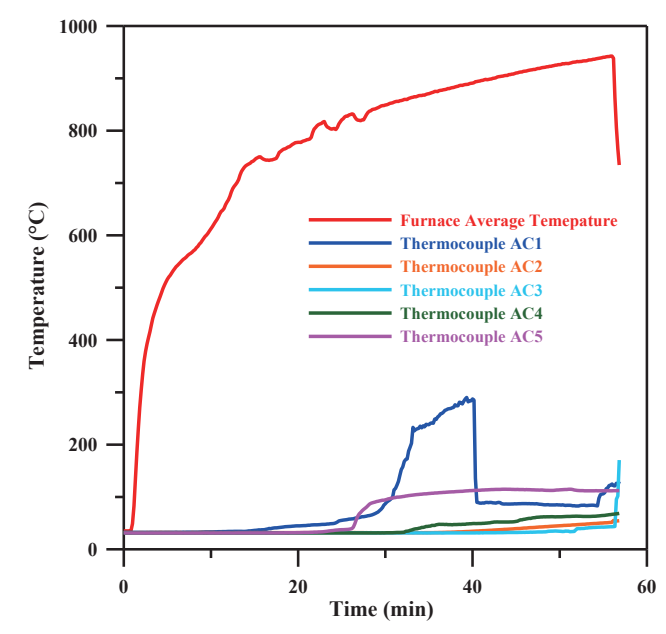

(a)

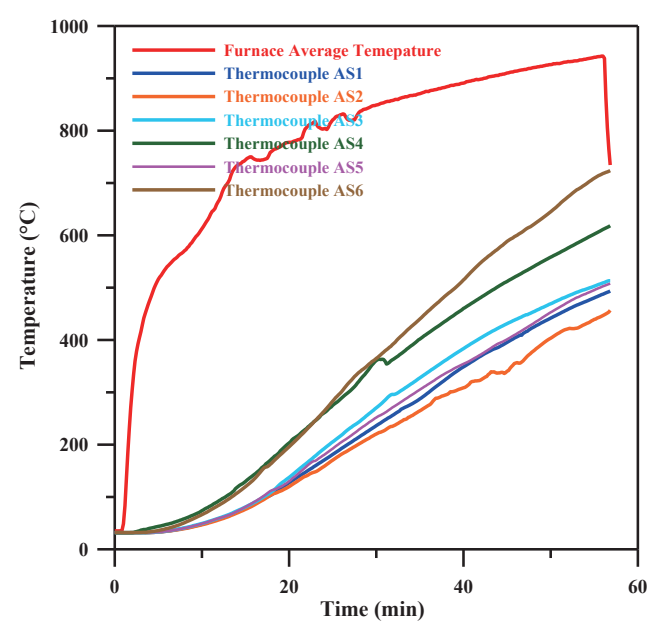

(b)

Fig. 6. (Color online) Measured temperatures at cross-section A of CP1: (a) temperature in the concrete and (b) temperature in the structural steel.

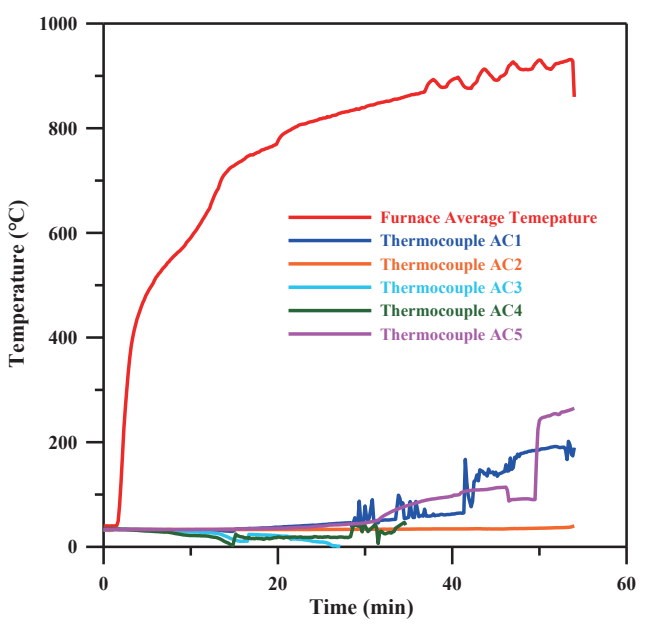

(a)

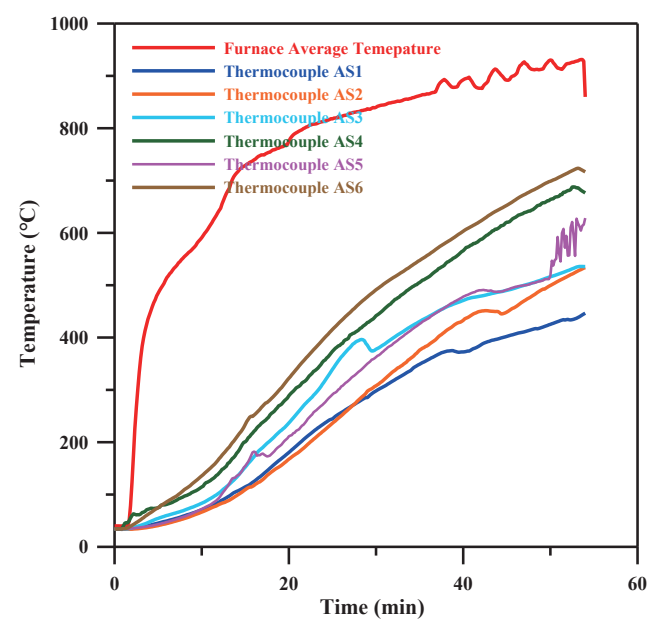

(b)

Fig. 7. (Color online) Measured temperatures at cross-section A of PP1: (a) temperature in the concrete and (b) temperature in the structural steel. 
The materials (i.e., steel plate, welding material, and concrete) used for fabricating specimens CP1 and PP1 were the same. The difference between the two specimens was only the welding method. Figure 8 shows the axial deformation versus time curve registered during the fire test and Table 2 shows the difference between axial deformations of the columns. From Fig. 8 and Table 2, the specimen behavior can be compared. It can be observed that at a fixed duration of the fire test, the magnitudes of axial deformation for specimen CP1 were lower than those for specimen PP1. It can be clearly seen from Table 2 that the axial deformation of specimen CP1 was approximately 0.36 to $1.43 \mathrm{~mm}$ smaller than that of specimen PP1 within $15 \mathrm{~min}$ after the fire test. During the fifteenth to the thirty-fifth minutes, the difference between the axial deformation of specimen CP1 and specimen PP1 was large and was between 2.13 and $2.65 \mathrm{~mm}$. The test results indicated that CP1 has better fire resistance.

A comparison between the predicted and measured axial deformations is shown in Fig. 9 for specimen PP1. From Fig. 9, it can be seen that in the first $35 \mathrm{~min}$ the predicted axial deformations fit with the measured axial deformations. After $35 \mathrm{~min}$, however, significant differences can be observed. On the other hand, Fig. 10 shows the specimen appearance after the test. It can be

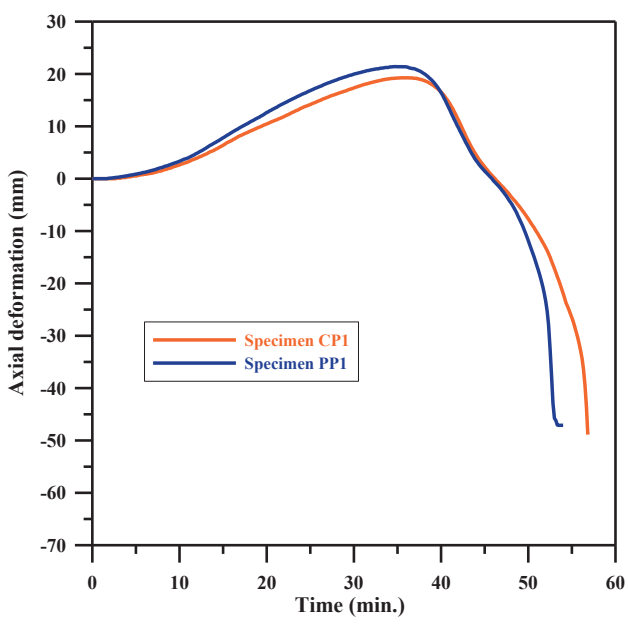

Fig. 8. (Color online) Comparison between axial deformation for CP1 and PP1.

Table 2

Axial deformations of tested columns.

\begin{tabular}{lcc}
\hline \multirow{2}{*}{ Fire time (min) } & \multicolumn{2}{c}{ Axial deformation $(\mathrm{mm})$} \\
\cline { 2 - 3 } & Specimen CP1 & Specimen PP1 \\
\hline 5 & 1.2 & 0.86 \\
10 & 2.63 & 3.33 \\
15 & 6.39 & 7.82 \\
20 & 10.45 & 12.64 \\
25 & 14.16 & 16.81 \\
30 & 17.34 & 19.97 \\
35 & 19.22 & 21.35 \\
40 & 6.55 & 16.43 \\
45 & 2.25 & 1.45 \\
50 & -7.69 & -11.83 \\
55 & -26.54 & - \\
\hline
\end{tabular}

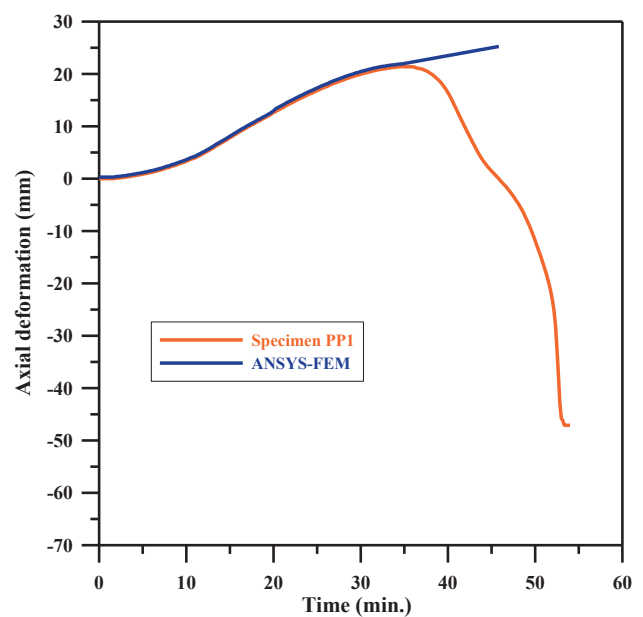

Fig. 9. (Color online) Comparison between the predicted and measured axial deformations for PP1. 


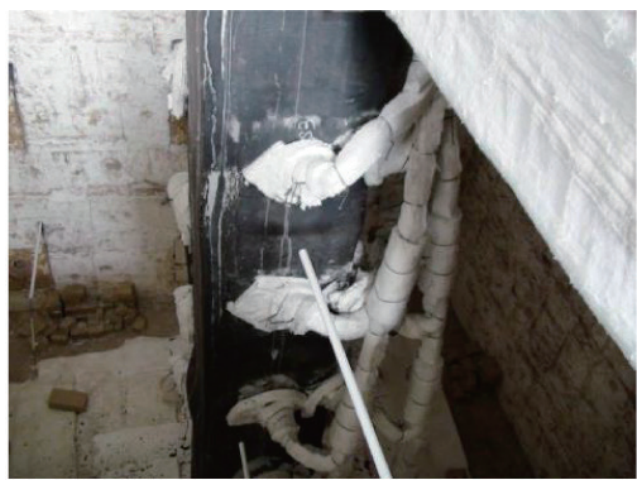

(a)

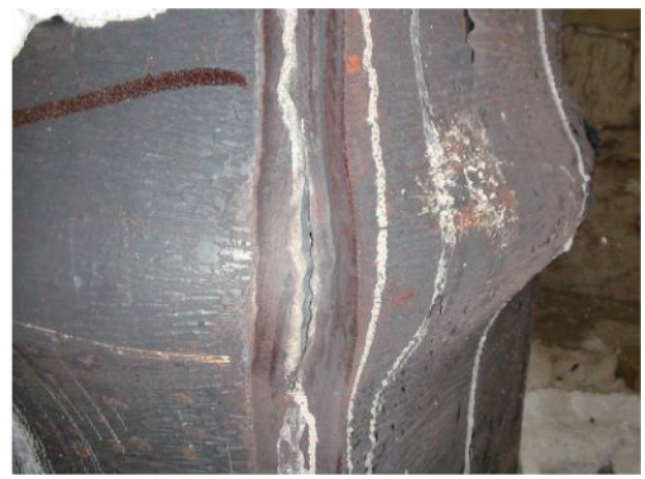

(b)

Fig. 10. (Color online) Appearance of CP1 and PP1 after the test: (a) specimen CP1 and (b) specimen PP1.

clearly seen that the final failure mode was the bulge of the column steel plate. As demonstrated in Fig. 10, the bulge of the column steel plate, which occurred at several locations, was observed.

\section{Conclusions}

In this study, the effect of welding methods on the fire resistance of CFBC was evaluated. In addition to the different welding methods, the two columns were made of the same material and were subjected to the same constant load. Differences in the results of the test were compared. As can be seen from the test results, there was no significant difference in the temperature distribution within the two specimens. The fire resistance of specimen CP1 is $55 \mathrm{~min}$, compared with $51 \mathrm{~min}$ for specimen PP1. The results from the fire tests indicate that, under a constant load corresponding to $28 \%$ of the nominal compressive strength of the column specimen, the influence of different welding methods on the fire resistance of CFBC was not very significant. Moreover, the established numerical model was able to reasonably predict the axial deformation of the tested columns.

\section{Acknowledgements}

This work was partially supported by the Architecture and Building Research Institute, Ministry of the Interior, Taiwan. The authors also gratefully acknowledge the helpful comments and suggestions of the reviewers, which have improved the manuscript.

\section{References}

1 S. Hong and A. H. Varma: J. Constr. Steel Res. 65 (2009) 54.

2 A. Bahrami, W. H. W. Badaruzzaman, and S. A. Osman: Lat. Am. J. Solids Struct. 10 (2013) 409.

3 A. Espinos, M. L. Romero, and A. Hospitaler: J. Constr. Steel Res. 66 (2010) 1030.

4 A. Espinos, M. L. Romero, E. Serra, and A. Hospitaler: Thin-Walled Struct. 93 (2015) 137.

5 L. H. Han, W. Li, and R. Bjorhovde: J. Constr. Steel Res. 100 (2014) 211.

6 V. Moliner, A. Espinos, M. L. Romero, and A. Hospitaler: J. Constr. Steel Res. 83 (2013) 137.

7 Z. Tao, M. Ghannama, T. Y. Song, and L. H. Han: J. Constr. Steel Res. 118 (2016), 120.

8 N. Mago and S. J. Hicks: J. Constr. Steel Res. 119 (2016) 123.

9 T. Ekmekyapar: J. Constr. Steel Res. 117 (2016) 175.

10 C. Frazão, A. Camões, J. Barros, and D. Gonçalves: Constr. Building Mater. 80 (2015) 155.

11 M. F. Granata: Constr. Building Mater. 96 (2015) 581. 